\title{
A Note by K. L. Johnson on the History of the JKR Theory
}

\author{
Valentin L. Popov ${ }^{1}$ (1)
}

Received: 20 August 2021 / Accepted: 4 September 2021 / Published online: 9 September 2021

(c) The Author(s) 2021

\begin{abstract}
The history of the following note is as follows. In 2003, I invited Kenneth Johnson to Berlin to give a talk on adhesion in a seminar at the Institute of Mechanics. His lecture on the topic "Mechanics of adhesion of spherical surfaces" took place on Monday, January 26, 2004. In the run-up to the seminar, Professor Johnson sent me a historical note dated November 18, 2003. In my opinion, this note, which was written in the form of a paper, may be of interest for experts in contact mechanics and tribology. Prof. Johnson did not publish it, so it remained a private communication. For a publication he might have made a revision and would possibly have credited other important contributions. But this we can only guess at, and therefore the note is published below in the form I received it from Kenneth L. Johnson, with only a few misprints corrected. It is interesting as a historical document from Ken Johnson, who played a key role in development of theory of adhesive contacts.
\end{abstract}

The history of the following note is as follows. In 2003, I invited Kenneth Johnson to Berlin to give a talk on adhesion in a seminar at the Institute of Mechanics. His lecture on the topic "Mechanics of adhesion of spherical surfaces" took place on Monday, January 26, 2004 (Fig. 1). In the run-up to the seminar, Professor Johnson sent me a historical note dated November 18, 2003. In my opinion, this note, which was written in the form of a paper, may be of interest for experts in contact mechanics and tribology. Prof. Johnson did not publish it, so it remained a private communication. For a publication he might have made a revision and would possibly have credited other important contributions. But this we can only guess at, and therefore the note is published below in the form I received it from Kenneth L. Johnson, with only a few misprints corrected. It is interesting as a historical document from Ken Johnson, who played a key role in development of theory of adhesive contacts. Another personal view on the history of the JKR theory can be found in the book by K. Kendall (Ref. [1] in the Johnson's note.)

Valentin L. Popov

v.popov@tu-berlin.de

1 Technische Universität Berlin, Str. des 17. Juni 135, 10623 Berlin, Germany

\section{The Background to the JKR Theory of Adhesion of Elastic Spheres by K.L. Johnson}

The Hertz theory of the contact of spherical bodies was published in 1882 . Why did it take almost 100 years for the theory to be extended to adhering spheres? A quick answer would be to say that it was such common experience that elastic spheres do not adhere, that no incentive existed to pursue such an impractical theory. However, the intervening years were not completely without activity, which I shall now briefly examine.

Physicists were well aware that adhesive forces exist, of high intensity, but of very short range (a few nanometres), such that adhesive strength was expressed in terms of the work required to separate unit area of the interface: the surface energy, analogous to the surface tension of liquids. As Kendall says in his recent book [1]: solids are expected to adhere; the question is to explain why they do not, rather than why they do! A notable early experiment which demonstrated the adhesion of lead spheres was conducted by Desagulieres [2]. Each sphere had a small flat. When the two flats were pressed together with a little twist they adhered strongly. The twist is necessary to produce plastic deformation of the surface asperities. In 1932 Bradley [3] showed that two rigid spheres would adhere with a force to separate of $2 \pi R \gamma$.

An important chapter in the story arose out of Bowden and Tabors' so called 'adhesion theory of friction' [4] in 


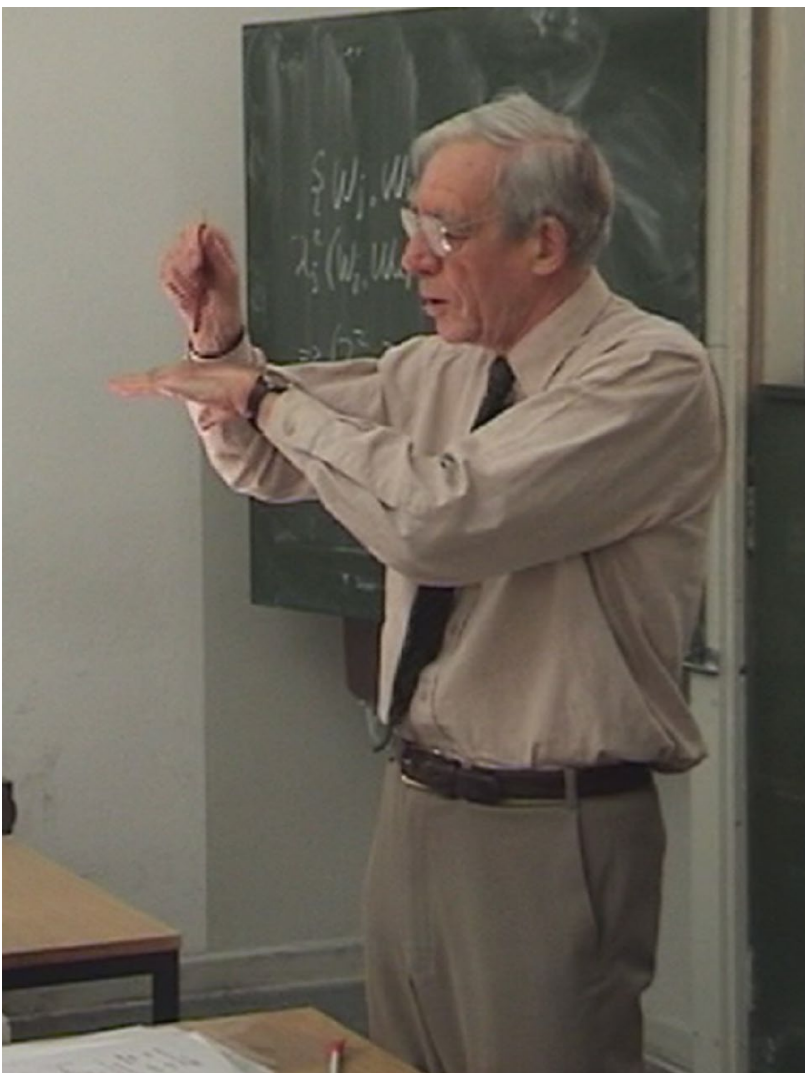

Fig. 1 K.L. Johnson during his lecture at the Institute of Mechanics of Technische Universität Berlin on January 26, 2004

which the resistance to sliding of clean metals was attributed to adhesion between plastically deformed surface asperities. Justification of this model gave rise to Tabor's researches into adhesion and surface energy. The theory was greeted with much practical scepticism on account of the apparent absence of observable adhesion, which was explained by the release of elastic deformation when the contact load was removed. In support of this explanation in 1958 I derived the distribution of surface traction between adhering elastic spheres [5] and, unaware of the Griffith's theory of brittle fracture [6], argued that the infinite tension at the periphery of the contact would ensure that the spheres would peel apart when the compressive load was removed. It is ironic to note that the stress distribution which was used in 1958 to prove that elastic spheres could not adhere was used in 1971 [7] to show that they could!

Tabor's work on adhesion and surface energy continued, taking advantage of the fact that molecularly smooth samples of mica could be produced by cleavage [8]. This led to the measurement of the magnitude and range of surface forces by Israelachvili [9], which formed the basis of the Surface Force Apparatus. Tabor was not the only scientist in the world interested in surface forces and adhesion. In Russia, B.V. Derjaguin [10] working on colloidal solutions considered the effect of deformation of spherical particles on their adhesion. This model-the DMT theory-which neglected the effect of surface forces on the elastic deformation was developed and published in English by Derjaguin, Muller and Toporov in 1975 [11].

About 1970 Tabor received a commission to investigate the behaviour-friction and lubrication-of wind screen wipers. The awkward geometry of wiper blades was quickly abandoned in favour of their standard arrangement for friction tests: a sphere sliding on a flat surface. To avoid surface roughness effects, a segment of soft rubber was cast in a good quality concave lens and placed in contact with plate glass. Alan Roberts, the student working on the project (now Deputy Director of the Malaysian Rubber Research Laboratory, U.K.) observed that when the compressive load was removed the contact area did not fall to zero, and that a measurable tensile load was required to separate the surfaces. Kevin Kendall (a fellow student, now Professor at Birmingham University, U.K.) made the suggestion that there should be some relation between the elastic energy of the residual deformation and the surface energy of the rubber-glass interface, leading to the 'approximate theory' included in [7]. They then approached me for help. It was a simple matter to calculate the elastic energy associated with the stress distribution in Ref. [5] to give the familiar result. Publication in 1971 produced an immediate response from Moscow which led to a rather acrimonious debate between Derjuagin and Tabor over the merits and deficiencies of the DMT and JKR models. The debate was resolved by Tabor's physical insight [12], who realised that both models were limiting asymptotic solutions to the general problem, at the extremes of a parameter which expressed the relative magnitudes of the elastic deformation and the range of action of the surface forces. To their great credit the Moscow group [13] produced the first full solution, later improved by Greenwood [14], covering the transition between the DMT and the JKR limits.

There are a few more things to say. Shortly after the publication of JKR [7], Savkoor (working on the friction of rubber tyres) came upon the Ph.D. Thesis of G. Sperling (1964) [15] which contains the principal features of the JKR theory and led to the fair suggestion that it should be renamed the 'JKRS theory'. The potential value of the Sperling's work does not seem to have been appreciated by the student or his supervisor, since no record of the work has come to light in the open literature. A photocopy of the Thesis can be obtained through the library of the TH Karlsruhe, but I have been unable to make contact with Sperling in person.

Although he did not appreciate it at the time Kendall's suggested energy balance forms the basis of linear elastic fracture mechanics and it was left to Maugis [16] to pursue this connection at length. 
The recent development in microprobe instruments has focussed attention on adhesion effects and given rise to the application of the JKR results, often in inappropriate circumstances, notably to inelastic solids. The situation is not then reversible and more work is required to separate the surfaces than is returned when they come together, a feature referred to as 'adhesion hysteresis'. The first application of JKR to plastically deforming spheres was made by Johnson [17] in 1975 and more fully by Maugis and Pollock [18]. Adhesion of viscoelastic solids is irreversible and rate dependent. It presents a difficult problem in contact mechanics and is an on-going field of research. See for example Johnson and Greenwood [19].

K.L. Johnson

1 New Square

Cambridge CB1 1EY

18 November 2003

Acknowledgements I am grateful to Prof. Johnson's children Andrew Johnson, Hilary Johnson and Marian Hallet as well as Prof. K.L. Johnson's widow, Dorothy, for permission to publish this note. I also would like to thank the Editor-in-Chief of "Tribology Letters", Prof. Spencer, for his support in finding a proper form of this publication.

Funding Open Access funding enabled and organized by Projekt DEAL.

Open Access This article is licensed under a Creative Commons Attribution 4.0 International License, which permits use, sharing, adaptation, distribution and reproduction in any medium or format, as long as you give appropriate credit to the original author(s) and the source, provide a link to the Creative Commons licence, and indicate if changes were made. The images or other third party material in this article are included in the article's Creative Commons licence, unless indicated otherwise in a credit line to the material. If material is not included in the article's Creative Commons licence and your intended use is not permitted by statutory regulation or exceeds the permitted use, you will need to obtain permission directly from the copyright holder. To view a copy of this licence, visit http://creativecommons.org/licenses/by/4.0/.

\section{References}

1. Kendall, K.: Molecular Adhesion and its Applications. Kluwer Academic, New York (2001)

2. Desagulieres, J.: Philos. Trans. R. Soc. Lond. 33, 345 (1724)

3. Bradley, R.S.: Philos. Mag. 13, 853 (1932)

4. Bowden, F.P., Tabor, D.: Friction and Lubrication of Solids (Chap. V). OUP, Oxford (1951)

5. Johnson, K.L.: Br. J. Appl. Phys. 9, 199 (1958)

6. Griffith, A.A.: Philos. Trans. R. Soc. Lond. A221, 163 (1920)

7. Johnson, K.L., Kendall, K., Roberts, A.D.: Proc. R. Soc. Lond. 324, 301 (1971)

8. Bowden, F.P., Tabor, D.: Friction and Lubrication of Solids II (Chap. V \& VII). OUP, Oxford (1964)

9. Israelachvili, J.N.: Proc. R. Soc. Lond. A 331, 39 (1972)

10. Derjaguin, B.V.: Kolloid Z. 69, 155 (1934)

11. Derjaguin, B.V., Muller, V.M., Toporov, Y.P.: J. Colliod Interface. Sci. 53, 314 (1975)

12. Tabor, D.: J. Colloid Interface Sci. 58, 1 (1976)

13. Muller, V.M., Yushchenko, V.S., Derjaguin, B.V.: J. Colloid Interface Sci. 77, 91 (1980)

14. Johnson, K.L., Greenwood, J.A.: J. Colloid Interface Sci. 192, 326 (1997)

15. Sperling, G.: Eine Theorie der Haftung von Feststoffteilchen an festen Körpern, Diss. Fakultät des Maschinenwesen. T.H. Karlsruhe, 1964

16. Maugis, D.: Contact, Adhesion \& Rupture of Elastic Solids. Springer, Berlin (2000)

17. Johnson, J.L.: Proc. XIV Int.Congress Th. \& Appl.Mech, p. 133, North-Holland (1976)

18. Maugis, D., Pollock, H.M.: Acta. Metall. 32, 1323 (1984)

19. Johnson, K.L., Greenwood, J.A.: Adhesion of Viscoelastic Spherical Solids. In: Martins, J.A.C., Marques, M.D.P.M. (eds.) Contact Mechanics, pp. 141-160. Springer, Dordrecht (2002)

Publisher's Note Springer Nature remains neutral with regard to jurisdictional claims in published maps and institutional affiliations. 